\title{
The Implementation of ERM in Non-Life Insurance Companies in Albania
}

\author{
Armanda Tola
}

\begin{abstract}
Enterprise risk management (ERM) has emerged a significant change starting from the way firms manage their complex portfolio of risks. Particularly, the insurance companies that use ERM have shown propensity of success during their daily operation and have been capable to diminish the collective risk of their output. This study draws attention to the performance, firm value and capital allocation effects of ERM adoption in emerging economies using the case of non- life insurance companies in Albania. The objective of the paper is to examine the effects trigged by ERM implementation on their firm value and the factors that caused it based on a structural and institutional theoretical framework. The sample is the population itself including all the non-life insurance companies which have implemented ERM from 2015 and on.

The methodology includes explanatory field study through semi-structured interviews with the key actors of risk management departments of these companies. This study distinguishes the impact of institutional and managerial pressures in adapting ERM in non-life insurance companies, based on empirical evidence and field study. The aim is to contribute in a better understanding of all the forces driving ERM adoption and implementation and the change in risk management practices and capital allocation within non-life insurance companies in Albania.

The findings identify the nature of internal and external factors which can be useful in creating new policies in relation of improving risk management systems and corporate governance.
\end{abstract}

Index Terms - capital allocation; ERM; firm value; risk management; non-life insurance companies.

\section{THE IMPORTANCE OF ERM IN INSURANCE COMPANIES}

The Committee of Sponsoring Organizations of the Tread (COSO) defined ERM as an outgoing process, directed by a unit's board of directors, management and other personnel, which affects the strategy setting within the enterprise, to identify possible occurs that may have an effect on the entity, and helping to manage risk to be within its risk appetite, in order to provide the appropriate protection regarding the accomplishment of entity purposes [1].

According to Harner [2] ERM may be seen also as a holistic approach in the pyramidal form which includes the identification, evaluation, and the responds to all the sort of risks: operational, strategic and financial one to achieve four main objectives: strategies, operations, reporting and compliance.

Some other studies like Beasley [3], Liebenberg \& Hoyt [4], Pagach \& Warr [5] show a growth in the ERM adoption and the appointments of Chief Risk Officers in different firms in certain industries. Kleffner, Lee, and Gannon [6] and Phang \& Burke [7] concluded that ERM implementation is different within industries while Colquitt, Hoyt, and Lee [8] found that ERM is more common in certain industries such as financial and insurance.

Insurers recognize Enterprise Risk Management (ERM) as fundamental in creating and improving shareholder value through better risk-based decision making and capital allocation. Tillinghast-Towers Perrin [9] conducted a webbased survey on risk and capital management issues. A total of 150 insurance industry executives worldwide responded. The survey indicated that the principal objectives for ERM are seen by insurers as helping them to create and improve shareholder value through better risk-based decision making and capital allocation. In addition, economic capital is a key decision making tool for insurers at all levels in their companies. Risk and capital management are making a difference in the insurers' business decisions which are now guided by enhanced risk and capital management approaches. These new practices are likely to be more frequent as their use increases in a wider variety of areas. The reporting practices of risk management and the level of success that insurers have experienced when integrating risk and capital management with performance management are also documented various reports.

It is argued that the best way to form an integrated risk management strategy is the interaction between the operations, capital structure and financial instruments of a company.

Some of the company's individual risks will cancel each other by aggregating risks together [10]. Three fundamental ways are required by a company to implement the objectives of risk management, which are: modifying the operations of the company, adjusting its capital structure, and employing targeted financial instruments. These ways interact to form the risk management strategy. The advantages and disadvantages of any specific approach should be weighed by managers to find an optimal mix of the three [10]. Effective risk management is correlated with well-managed business.

More specifically, insurers have an incentive to manage capital costs through risk management. Effective risk management provides a protection against unexpected losses which can primarily obtained by maintaining an appropriate level of economic capital by financial institutions. How much risk each business segment contributes to the total risk of the company and thus to overall capital requirements is estimated by the risk management process. More(less) risky lines may require more(less) capital and thus demand higher (lower) 
prices [11]. This is not clearly investigated or examined empirically in the literature.

Risk management matters to financial institutions because holding capital is costly and they face convex costs of raising external capital. It is argued that capital should be allocated in a way that the marginal contribution of each business line to the insolvency put value is equal [12].

The 2010 ERM survey conducted by AON showed that advanced ERM practitioners report significant success in applying ERM strategies to board-level responsibilities. It indicated that 57 per cent of the companies surveyed embed risk management within the process of capital allocation. This implies that ERM is affecting the capital allocation practices and driving the whole process. The survey results also revealed that companies with more mature ERM programs are able to manage this process in a better way bearing in mind that the amount of capital to be allocated is finite. However, companies in the early stage of the process report that they do not use ERM for capital allocation process [13]. Thus, ERM maturity level can be considered as affecting the level of its usage for allocating capital processes.

Ashby [14] stated that despite the insurers' efforts to launch ERM, underwriters and actuarial support has traditionally been at the center of organizational risk thinking. This implies that risk has been always a key issue considered by the people who mainly deal with capital. Thus, ERM is expected to drive a change in capital allocation practices as it changes the way of viewing and dealing with risks.

Regulator or statutory supervisors, as well as credit ratings agencies, focus on that any re/insurance company should remain solvent, which requires that company to measure and manage all risk types across the company. This supports the argument that an enterprise-wide approach to capital management across all risk classes (liability or hazard risk, asset or financial risk, and business risk) should be adopted by re/insurance companies [15].

Although academics and practitioners have shown considerable interest in ERM and survey evidence has been largely presented on ERM prevalence this lack of apparent empirical evidence on the impact of ERM continues to limit its growth [4].

Also, authors like Pagach and Warr [16] studied the determinants of the companies that had implemented ERM. The authors found that firms that are more leveraged, have flexible earnings and show lack of stock market performance are more disposable to start using the ERM program.

In the last years, the concept of Enterprise Risk Management (ERM) has earned substantial value and many firms have included systems and processes to implement an integrated and coordinated company approach to identify, assess and manage the risk. These processes and systems prevent that the total portfolio of risks exceeds the acceptable limits. Starting from 2015, non-life insurance companies in Albania are obliged to implement ERM in their risk management systems, supervised by the Albanian Authority for Financial Supervision, under the framework of ORSA. Even though, they are in different stages of implementation facing challenges that may be specific for each of them.

\section{RESEARCH DESIGN}

The interpretive approach helps to explain the changes in risk management practices after the ERM implementation. This is considered to be the most appropriate approach because of the social nature of the research. It provides an appropriate approach in investigating the problem of this research as it is defined in terms of social phenomena. The interpretive approach is coherent with the objectives of the study because it is subjective, meaning that it relies on perceptions and their point of view in interpreting various social and human activities [17].

Other studies in the field of accounting and management have used the interpretive approach. According to Burns [18], to dismount a certain phenomenon is important to consider its historical, economic, organizational, social, and institutional context. This is the reason why I choose to study ERM in its premises in order to interpret it on how people understand it. Even though the disadvantages of this approach are linked with rigor and subjectivity [17].

\section{A. The field Study Methodology}

Field study methodology is useful because field studies are mostly used to explore relationships, in this case the relationship between ERM implementation and risk management practices.

Field studies improve the understanding of the theoretical constructs that are studied empirically. They concentrate on the contextual influences of the constructs [19]. The social and organizational nature of the phenomenon under study justifies the choice of field study methodology to explore ERM adoption drivers and implementation determinants in the context of non-life insurance companies. As the population itself of eight large or medium-sized non-life insurance companies were at the same time the sample of this research.

An interpretive approach is more relevant than only collection and analysis of the data. In this research beside interviews, we used multiple methods to collect data such as semi-structured interviews, analysis of documents, and public available data analysis.

\section{B. Methodology}

In my study I used purposive sampling because of focusing only on some features and processes, choosing the appropriate persons to be interviewed. Denzin and Lincoln [20] emphasized that a lot of qualitative researchers employ purposive sampling method, not random ones. Their sampling includes groups, settings and individuals which are related with the processes that are being studied. The setting that I choose for my research is 'intrinsic' and 'instrumental' according to Silverman [21]. It can be considered as intrinsic cause there is no knowledge of the manner of how ERM affects risk management practices and instrumental because it can contribute to the ERM literature and rapidly changing environment. I chose the companies that responded to have adopted ERM and its systems, out of which I interviewed seven Risk Directors, two actuaries, a Director of Operational Risk and a Director of Economic Development who agreed to meet. The interviews were conducted in the premises of the insurance companies. In conclusion, I managed to conduct 12 semi-structured interviews as presented in the table below 
(Table 1). The company's, that have capital over 20 million Euro, were considered large, those between 10-20 million medium and those with capital lower than 10 million euro were noted as small. The financial data was derived from the financial statements of the year 2019, published from the Albanian Authority for Financial supervision.

TABLE 1: NON-LIFE INSURANCE STAFF THAT WERE INTERVIEWED

\begin{tabular}{|c|c|c|c|}
\hline Company & Size & Interviewee & Code \\
\hline 1 & Large & $\begin{array}{c}\text { Chief of } \\
\text { Risk Department } \\
\text { Actuary of the } \\
\text { company }\end{array}$ & CRD-1 \\
\hline 2 & Large & $\begin{array}{c}\text { Chief of Risk } \\
\text { Department } \\
\text { Chief of Finance } \\
\text { Department }\end{array}$ & CFD-2 \\
\hline 3 & Medium & $\begin{array}{l}\text { Actuary of the } \\
\text { company } \\
\text { Chief of Risk } \\
\text { Department }\end{array}$ & ACC-3 \\
\hline & & $\begin{array}{l}\text { Director of economic } \\
\text { Development }\end{array}$ & DED-3 \\
\hline 4 & Medium & $\begin{array}{l}\text { Chief of Risk } \\
\text { Department }\end{array}$ & CRD-4 \\
\hline 5 & Medium & $\begin{array}{c}\text { Chief of Operational } \\
\text { Risk }\end{array}$ & COR-5 \\
\hline 6 & Small & $\begin{array}{c}\text { Chief of Risk } \\
\text { Department }\end{array}$ & CRD-6 \\
\hline 7 & Small & $\begin{array}{l}\text { Chief of Risk } \\
\text { Department }\end{array}$ & CRD-7 \\
\hline 8 & Small & $\begin{array}{c}\text { Chief of Risk } \\
\text { Department }\end{array}$ & CRD-8 \\
\hline
\end{tabular}

According to Creswell [22], the semi-structured interviews have the advantage of allowing the interviewer to change the questions, in accordance of the direction of the conversation, and to expand the discussion on the topics on which the interviewer or the interviewee seem to convoke more interest in when is needed.

The main focus of the questions imposed in the interviews is related with:

- the role and responsibilities of the interviewees.

- their work experience and background.

- their involvement in adapting and implementing the ERM process.

- the required time of implementing.

- the adoption drivers.

- implementation issues and problems.

- the changes in risk management practices that come from ERM implementation.

\section{INVESTIGATING ERM ADOPTION AND IMPLEMENTATION}

Risk is a relatively new concept that is starting to gain relevance in the recent years in both private and public companies. Insurance companies since about 6 years are supervised by the Albanian Authority for Financial Supervision focused on risk in relation to their activities. The risk management process is the application of a systematic process of understanding a series of events that can occur, how they can occur, when and why they can occur. The more accurately we answer these questions, the more correctly we will address the identified risks by not only focusing on the "known" risks but also taking measures for those that could potentially occur or for other risks that we do not know if they will happen.

Risk identification should also identify existing controls that are intended to modify, prevent, or avoid undesirable or negative consequences as well as the probability of their occurrence.

"The key to success in identifying risks is to involve as many people as possible and think of all the possibilities and events that can occur no matter how rational, obvious or meaningful they can be considered at this stage of the risk management process." (ACC-1).

The identification of risks will include an assessment of the environmental factors in which the institution carries out its activity, organizational culture and the goal or objectives set. A special attention should be given to the expected results from risk management, assumptions, limitations, cost / effort estimates, available resources.

The identification of risks consists in determining which aspects are likely to be affected and documenting the characteristics of each of them. Risk identification should address the identification of internal and external risks. The main sources of risks that have the potential to cause a major effect should be identified and classified according to their impact, timing and set objectives. Risk identification uses historical and current information and data making it a necessary step in the early stage of assessment and should occur prior to detailed risk analysis and dissemination.

The Risk Identification process goes through some stages:

1. Identification of the sources of risks.

2. Risks that could potentially occur.

3. Identification of perspective "symptoms" of risks.

4. Relation to processes, activities, or other events

5. "Validation" of risks.

The information or basis on which these risks are identified should be checked for the accuracy of the descriptions or sources from which they were obtained.

The risk identification process is about identifying events that may affect the society's objectives: "What can happen?" These risks can have a positive impact (opportunity / opportunity) instead of a negative impact (threats) on society's objectives. Risk identification should start with the senior management of the Board to continue down through the various levels of management. However, it is unlikely that one risk identification technique will be sufficient to identify all the risks for the good management purposes of the company and the achievement of the main objectives therefore a combination of techniques should be used.

"Some of the risk identification techniques used in our company include:

- workshops (brainstorming sessions) moderated by the risk management unit to answer the question; "What could go wrong".

- Individualized interviews with participants in the processes, activities or events discussed in the risk identification process.

- Questionnaires and surveys.

- On-site inspections, various analyzes, etc. ”- (ACC-3). 
2015 was the year when the companies in Albania implemented ERM as part of their risk management strategy and most of them re-organized their structural composure according to the philosophy of Enterprise Risk Management, based on legal and regulatory requirements. As one CRD-1 answered:

"assigning and training human resources for the Risk Management; preparing and approving the necessary internal acts; organizing internal trainings with the Supervisory Board, Senior Management and Operational Management, in order to create a Risk Culture was challenging even though we started the preparation from the late 2014",

as he cited: starting from 2016 onwards, the relevant products (reports, analysis, etc.) are provided for the purpose of Enterprise Risk Management for the governing bodies of the Insurance Group, Financial Supervisory Authority, etc.

\section{INTERNAL AND EXTERNAL PRESSURES}

Before implementing ERM, these non-life insurance companies, same as the entire insurance industry in Albania, were applying the traditional approach and the main problems according to the CRD-1 were: the lack of organizational structure, human resources, internal acts, etc.

According to the actuaries the ERM process is mostly dictated by internal business indicators but also in parallel with the increase in the requirements of supervisory authorities, and which will soon lead to an increase in the capital and solvency ratio of insurance companies.

"the main influencers of ERM adaptation are the human resources, internal regulations and the IT systems" (CRD-2)

\section{A. Regulative Pressures}

Regulative pressures, trying to surpass the effects of the financial crisis and meeting the requirements of Solvency II for the future, have speeded up the implementation of ERM in non-life insurance companies in Albania, emerging to create also the 'culture' of well-controlled risk management systems. The regulations highlight the relevance of ERM, and they improve the velocity of adapting risk management processes and programs. The main reason behind these regulations is the financial strength of these companies, which is a contributor in the financial stability of the country.

Some of the legal and regulatory requirements that are mandatory for adapting ERM that they mentioned during the interviews were: Financial Supervision Authority; the positive will and requirements of the Shareholder, the Supervisory Board, and the Senior Management.

The adequate use of ERM might be create in the future competitive advantages compared with the other companies that show less productive result from the implementation according to the risk officers. That is why non-life insurance companies should not suffice only with the compliance of the regulations but should develop it further according to the need of their companies. Regulative demands are seen to have more impact on the strict areas like capital allocation, and less impact in flexible issues like for instance management decision-making issues.
About the fact if the ERM process is dictated by government and institutional requirements, one CRD-1 responded that: "is not about 'dictation', rather than about a positive impact (requirement) for the implementation of the criteria set out in the Law "On insurance and reinsurance activity" and regulatory acts in and for its implementation.

They see it as a positive fact that the regulations are finally putting companies in the same line of performing risk management:

"however is a positive fact that we are compiling with the same directions, the key is to use it in our favor in the sense of knowing the amount of capital, we need to hold within the company in order to run all the risks that we face as a company."

\section{B. Competitive Pressures}

Some of the risk officers interviewed (CRD-1; CRD-3; CRD-4) accept the fact that the competiveness within the insurance market, plays a role in the adaption of ERM. The rating from the private auditory companies in terms of risk management as strong or medium-strong is an indicator of how well the implementation of ERM is in these companies.

"There has always been a tendency of being superior in the market, starting from the financial indicators that are the key of the "wellbeing" of our company. Even when we were a public company it was always a duty to monitor the risk coverage limits, now that the market is highly competitive, this demand has only been increased perpetually." (DED-3).

\section{Qualification and Education}

It has been found that the implementation of ERM depends on the education and qualification of risk managers/directors. The process is "delicate" enough to require a staff with professional background in the field of risk management.

"Personally, I think that the education in the university, concretely in the areas of economy or mathematics is a good start if you want a career in risk management sectors. After that, of course there is a lot to learn through experience at work itself. I've been very lucky to work in a company where there is a goodwill to invest in human resources capital, therefore I have participated in various training programs and seminars to be in the position where I am now. Absolutely I support the fact that the implementation of ERM in our company wouldn't have been possible without the preparation of a qualified staff'- (CRD-3).

All the interviewees support the fact that the qualifications and professionalism of the persons included in the process of risk management increase their attachment with several aspects of business that bring out better risk management decisions. The experience of different persons of various sectors should be considered during the adaption of ERM to create an overview of the whole factors that might affect the process.

“... as a risk manager, my job experience has included previous occupations in the fields of operational management, audit or finance management."'-(CRD -4). 
It is logical that there is a strong relation between risk management functions and actuary ones, since they both operate in the same line and have contributed substantially to the facilitation of ERM implementation. Actuaries are specialized in creating mathematical and statistical models to assess all the systematic and non-systematic risks the company may face. They can explain and enforce the strong relationship between ERM and capital allocation management, even though there is no class that might teach it completely theoretically, it is rather a process that is learned through practicing.

"I think that the development of the market, the increase in the consumer's demand and at the same time, the increase in the cases of insurance fraud, created the demand for the implementation of international standards that had an impact on the adaption of ERM and of other standards in general". (COR-5).

"The ERM process was mostly dictated by internal business indicators in parallel with the increase in the requirements of supervisory authorities, and which will soon lead to an increase in the capital and solvency ratio of insurance companies. The qualified staff is a necessity for the adaption, but also continuing education as an integral part for the market growth". (ACC -1.)

The chief risk officers support the idea that the staff education and qualifications affect the ERM implementation process. Trying to encrypt the ERM adaptation process within the company, I asked them to define it as a radical system change or as a major change within the existing system. One of them explained it as: "from the point of view of Risk Management philosophy, I consider it as a radical change, while from the point of view of practical implementation, I consider it to be major changes within the existing system, extended in time and carefully applied". (CRD-1). CRD-2 considers it as a radical change in the existing system.

\section{The Shareholder's Pressures}

Evidence has demonstrated that shareholders have a crucial part in how ERM is implemented in the companies. Shareholders are always concerned about their company's position regarding to risk exposure; therefore, they have all supported the pursuit of a more sophistication robust risk management system like ERM.

\footnotetext{
"it was a good will and a consent from all the stakeholders, especially from the main shareholder, to implement the ERM process"-(CRD-4)
}

The investors try to possess an effective control over the forces that may 'harm' or threat their firm health and directly push their management board to be in charge of it.

\footnotetext{
"Managing risk is, not only at our company, but I suppose in every insurance company, the core arteria of the business lines. Everything else depends from risk management, each other sector. It is understandable that the shareholders have an impact on how ERM is implemented, partially or
}

completely. They monitor from the top that everything is going according to their plan" - (COR-5).

\section{E. Other Internal Pressures}

Those companies that had implemented ERM, have Risk Management Chiefs that are fully engaged in the implementation of ERM in their companies. The persons that I interviewed were chosen intentionally to be fully involved, with maximum commitment in the risk management field, considering also their organizational position.

"I am fully involved in all the processes starting from the construction of policies and regulations to the inventory of risks and the production of frequency / severity matrices" (CRD- 2).

As one of them mentioned, based on the positions covered during the career "I believe I have played a key role, but I have also unreservedly supported all the steps taken by the shareholder decisions of the Supervisory Board and Senior Management. (CRD-1).

The dedication of the staff itself and of the persons in charge is a key factor in the adaption of ERM.

“... before passing the information and education to the other part of the staff, it was necessary for me to read through all the information I could gather from internet and other sources about the benefits that ERM brings to the firms. Only by convincing and educating myself primary, I could further embed ERM within the organizational levels of our company”. (CRD-1)

All the departments are an integral part of the process, especially risk management and claims department, the department of underwriting, the legal department, as well as the board of directors of the company.

"In the early stages of the implementation, it was necessary to find the adequate required professional staff to conduct the training, and after that the issue was to train and qualify the staff who would follow the processes. The implementation of the system itself is a key factor in the automation process in order not only to minimize the operational manual work but also to generate important reports for risk analysis”. (CRD-6).

It was from the beginning that ERM was accepted as a new methodology that would help risk managers to meet different company objectives among which they emphasize:

$\checkmark \quad$ taking decision based on risk assessment.

$\checkmark$ improve the performance of the company.

$\checkmark$ improve the costumer's confidence on insurance products.

$\checkmark$ facilitating the share of information about risk in real time.

$\checkmark$ creating a "honest environment" for the market concurrence.

$\checkmark$ etc.

Summarized, as a conclusion, both internal and external factors have been drivers of the adaption of ERM and the people included themselves have shaped the way the 
implementation is being processed in each company specifically. Their significance is difficult to be measured, since they are qualitative factors that affect the process holistically.

\section{ERM AS AN EMBEDDING PROCESS}

Before implementing ERM, risk management was a traditional one, that means it was focused on operational risks. The traditional risk approach presume that each department is only responsible for itself, and each Chief of department should calculate their risks independently (for instance the Chief of Underwriting asses only underwriting risks). The main problem of traditional risk is that it neglects the possible relationship between risk, summarizing them. The risks might be correlated negatively or positively with each other, and this is the difference that brought ERM assessing the aggregate risk not simply as a sum of risks.

"The implementation of ERM is a step that requires time to be fully adapted from all the departments and is costly for the company. The main difference that ERM brought to our company is the fact that the information is now on real time. The methodology of ERM has gathered the best aspects of all the risk methodologies of the insurance companies during the years." (ACC-3).

CRD -2 responded that in his company before implementing ERM, the risk management system was included in the other departments. Two companies explained that before the adaption of ERM they were using a system where capital was subdivided according to the business lines (emphasizing the weight of each product).

"Before implementing ERM we had a kind of autocratic approach, where we prepared individually reports, without very much consulting between the sectors. ERM brought a big change on how the process correlates the different patterns of work."-(CRD-7)

Another chief of risk department made a comparison:

"If I could use four words to describe the risk management before the implementation of ERM, they would probably be: automatic, informal, operational and strict. I think that from five years now things have changed a lot in our department in terms of monitoring and managing, but still the framework needs to be settle completely. We are not yet in the final phase" (CRD-7)

Some others think that they have adapted completely ERM and no- adjustments should be done from the confront:

"We are in the final stage, where special products are produced" (CRD-2)

but they responses seem to be controversial since they yet have not noticed radical changes in the capital allocation.

Even though, starting from 2011-2012, some of the nonlife insurance companies (half of them according to the respondents) began the process of creating a sort of framework for reporting on risk management. Those companies that had already done it, facilitated the process of transiting to the system of ERM in 2015, when it became obligatory. The education and a continuous lobbing pro the implementation of RM has facilitated the whole implementation process. Another key factor has been the financial support from the shareholders. The financial support is seen more in terms of professional support and creating the adequate structures for risk management purposes.

"ERM has been challenging in terms of changing the work culture in non-life insurance companies in Albania. It is hard to induce in the persons that work a new culture with a focus that has moved towards being more opened and responsible... challenging the previous manners that were used in internal reporting. Since the process requires people with "multi-dimension" skills, people that know well every detail of risk management, instead of hiring new people the actual staff was trained with the new approach and methodology of work. Our work has been facilitated in some aspects but now we have more duties than before." (CRD-6).

Before implementing ERM, all the insurance companies had only a Chief of Risk Department without a staff, now several people work in a coordinated way to comply with the reporting. Even though the group work, finding qualitative data is still difficult they admit.

"A difficult event that required a lot of efforts from our part as risk management team was the earthquake on November $26^{\text {th }}, 2019$ in Albania, which didn't find us very well prepared. Also, the pandemic that is happening now, was impossible to be predicted in advance. Always, when talking about catastrophic events, it is challenging to predict approximately what may occur, because of the frequency of these events might be one in a century. Their low frequency complicates the creation of a model that includes all the risks that might arise from these events.

So, in summary, the lack of qualitative data and of a proper model, complicated our work, even though the implementation of ERM." (CRD-3).

Sometimes, changes are not so evident and can be difficult to be noticed from the beginning of the implementation of ERM.

"Changes are evident in our company, but the problem in some cases is the fact that risk can be transformed from hidden factors that are difficult to be detected." (CFO-4).

Another challenging aspect of embedding ERM in non-life insurance companies seems to be (six out of 9 respondents mentioned it during the interview) the technology used to assess the risk. Most of the companies are using old software$s$ that do not fulfill all the requirement for a fully implementation of ERM. An adequate software helps with creating a holistic and fast embedding in all the departments of the organization.

"if you do things only for the outside sight not from inside, you get to fool yourself! Because from the practical side, nothing changes. I would like to change the software that we 
are currently using because it doesn't provide all the data that we need in real time. For example, if I need extra information, but the software is limited in processing it, the results that I will provide in the end won't be completely exact as they should. Maybe after a couple of months, when all the data have been achieved and proceeded from the software I might calculate the proper results, but in the meantime the decision from the management departments have already been taken and executed." (CRD-6).

At last, implementing ERM in Albania is expensive according to them. In developing countries like Albania, it requires a lot of financial efforts to educate, qualify, hire persons that will operate in risk management with ERM, especially when the sources are limited. Another problem is the lack of culture in risk management, which is a huge handicap that affects all the factors mentioned before.

"Implementing ERM is very expensive, that is the reason why we have only completed with the main regulations without fulfilling all the details required. You cannot pretend to have a deep implementation when the structure has still haven't been created and we still use operational manners to calculate risk. It is difficult for our company to invest on ERM while we still haven't all the granted funds needed to implement it." (CRD-8).

The main problems that were encountered during the implementation and embedding of the ERM vary from one company to another, but generally from the respondents they can be compressed as:

-The initial lack of culture for enterprise risk management and corporate governance;

- A misunderstanding in the first steps about the important role of the key Internal Control Functions (Internal Audit, Risk Management Function, Compliance Function, Authorized Actuary). (CRD-1)

-Interaction between departments, creation of regulations $(C R D-2)$

Some of the companies that already have adapted ERM, have implemented everything required in the legal and regulatory provisions; in some aspects, they might even have surpassed them. As they note: the challenge remains the consolidation and standardization of the steps taken.

From the responses that were given I realized that different persons in the same positions in different companies have different perceptions about the process of embedding and implementing ERM. Some think that ERM is in the first phases of being implemented, some responded that only partially they have implemented, and the others opinion that are in the final stages of implementation. Each company despite their similarities, has its own specific workorganizational culture that has its effects on risk management practices, including ERM.

"We are in the final stage, where special products are produced" (CRD-2).

Another responded about the phase in which its company is a:
"We are still in the process of developing and improving processes" (ACC-2).

\section{Changes in CAPITAl Allocation}

An aspect that was asked to the Head of Risk Management Department was to explain if the implementation of ERM had influenced the change of capital allocation in their companies.

"The implementation of ERM has not yet influenced the change of capital allocation in our company." (ACC-1).

The implementation and use of ERM reduces seems to increase the demand for capital, strengthening the position of the company. CRD-1 agreed that it did, adding that "the annual report on the Risk and Solvency Self-Assessment also analyzes in detail the Solvency Risk, which provides the relevant conclusions and recommendations. Nevertheless, decisions in this regard are constantly consulted with the Financial Supervisory Authority, according to regulatory requirements". (CRD- 1)

Even after the application of Solvency II, the capital doesn't seem to be going through drastic changes, the risk officers respond. One of them claims that:

"I think that the implementation of ERM has influenced the change of capital allocation, but yet not completely, since the insurance companies, being under special supervision, have defined rules on the allocation of capital that meet the applicable legislative standards". (CRD-2).

The actuary of the company 1 (ACC-1), claims that after the application of Solvency II, there will be big changes in the allocation of capital even though the implementation of ERM has improved risk decision making by making it more strategic and facilitating the whole process.

"Definitely, there will occur changes, because the model of which capital is calculated will change. The changes in the which capital is allocated after the application of Solvency II, can even go further if companies are able to produce an "internal model" and adopt it." (CRD-7).

Currently, still three companies admit that the capital in their companies is allocated according to the methods of Solvency I and some other individual internal methods.

"Applying the philosophy of Corporate Governance in the current period and in the future until the Solvency Directive II is applied in the insurance market in Albania, I think will facilitate this process." (CRD-1).

The aspects in which the capital allocation changed, before and after the adoption of the ERM in the companies are related with the changes occurred in the second half of 2014 and 2015, according to the deadlines set out in Law no. 52, dated 22. 05. 2014, "On insurance and reinsurance activity", respectively the requirements of Section III - Capital Adequacy, Articles 80 and 81. 
"The allocation of capital within the insurance companies is guided by applicable financial standards. Changing these standards would also change the allocation of capital". (CFD-2).

Even though, there are changes in the allocation of capital according to the risk portfolio undertaken by the specific company and the insurance group itself (as was in fact the case of a company that was involved in buying companies in the insurance market in Albania, Macedonia and Kosovo). For this specific case, I interviewed the Director of the Economic Department in the company which responded that ERM helped to assess all the elements of risk before deciding to have an expansion in the market.

"ERM was the methodology used to measure the contribute of risk in a huge strategic decision of expanding in the market, as was that of buying new companies. A selfassessment report based on ERM methodology was prepared to ensure the Shareholder and the Board of Management that the decision of buying new companies wouldn't endanger the financial position of the mother company"-(CED-1).

\section{Changes IN DUties AND RESPONSIBILITIES}

CRD- 2 made a classification of the main stages / phases that the ERM process has undergone in his company as follows:

- Structural reorganization of the company and the Insurance Group according to the philosophy of Enterprise Risk Management, based on legal and regulatory requirements.

- Assigning and training human resources for the Risk Management functions.

- Preparation and approval of necessary internal acts.

- Internal trainings with the Supervisory Board, Senior Management and Operational Management, in order to create a Risk Culture within our company.

- Preparation and distribution of relevant products (reports, analysis, etc.) under Risk Management policy for the governing bodies of the non-life insurance company and group, the Financial Supervisory Authority etc.

"ERM cannot be seen as a process that started immediately at a certain point in time but rather as a continuous process. Meanwhile, for 3 years now the process has been formalized leading the company towards a practice of conducting early warning tests focusing the assessment of risk"'-(ACC-1).

While here too the problem was the professional design of all the necessary modules which should be programmed.

Risk Management process generally involves all the governing bodies and structures of the company, whose employees carry out risk management on a day-to-day basis, according to the roles and responsibilities that they exercise. However, the main coordinating sectors that are engaged are: Risk Management Directorate and Sector, Information Technology Sector, Analysis and Statistics Sector and the Authorized Actuary.

According to the actuary:
"The ERM adaptation process is seen for now more as a change in the development of existing systems but that definitely with time will be visible in radical changes' (ACC3).

An aspect that has changed in all the companies after the implementation of ERM is for sure the work of underwriters, who now use more tools to have more information for new premium. Their decisions on sales and underwriting are now more focused on risk, and the interaction between risk management department and underwriting department has increased.

CRD-1 agrees that ERM enriches the information among the company and help underwriters to take better decisions regarding to underwriting premium, having a better quality of information.

\section{Changes IN Risk Management PRACTICES CAUSED BY ERM IMPLEMENTATION}

All the interviewees of the companies that have already implemented ERM in their companies strongly support the fact that ERM has changed the risk management methodology in their companies. Mostly they distinguish that the aspects of the company that have been most influenced by the implementation of ERM are:

- The philosophy of management of the company as a whole and at all levels.

- The necessary structural adjustments at the societal and group level.

- The preparation and approval of internal acts, as well as monitoring their rigorous implementation.

- The product quality (reports, analysis, etc.) for the Shareholder, Supervisory Board, Senior Management and Operational Management.

"ERM brought substantially changes in organizational and regulatory aspects" (CRD-2).

The head of Risk Management agrees that the implementation of ERM has improved risk decision-making by making it more strategic. He argues that:

"...our company has been working on the basis of a fiveyear Strategy (2016 - 2020), Risk Management Strategy (annual basis); Annual business plan in which, among others, are set priorities through strategic and specific objectives. Relevant reports and analyzes are based on the progress of achieving strategic and specific objectives, etc." (CRD-1).

\section{Changes IN The Work OF Risk MANAgEMENT DEPARTMENT}

As discussed before, ERM is considered matured in a company, when is embedded and lied in all aspects of the company with an appropriate framework. A mature level of ERM, brings as a result, benefits for the company. The final advantages consist in a holistic understanding of risks and a reduction of the capital needed. But still the results need time to be seen. 
"Maybe, the best result that we have achieved till now, is to avoid some risks that might have had big effects on the company." (CRD-5).

Before implementing ERM, companies were focused only in registering and assessing risk without focusing on the allocation of capital. Studies have emphasized a strong relationship between the maturity of ERM and capital allocation. When the capital allocation changes are noticeable, is an indicator that the companies are ready for the new directive Solvency II.

"An aspect that has changed, after the implementation, is that more information related to the risk and capital is provided to the management board than before. This information is used in each meeting that the board organizes to make decisions". (CDR-4).

\section{Changes in Revenues Caused by ERM IMPLEMENTATION}

The implementation and use of ERM according to the interviewees do not cause changes in revenues over the years. They deny this adding that:

"on the contrary, by having a positive impact on the rigorous implementation of all legal and regulatory requirements, it also has a positive impact on the revenue indicator. But in addition to internal factors, external factors, especially political, economic, social and legal factors, have a significant impact on the income indicator".

At last, the effect of the implementation is not yet visible in these companies since it started only five years ago. According to them it would require approximately a decade of full implementation to see concrete results on the revenues affected directly from ERM.

"Revenues are a complicated indicator which cannot be decoded only from one element. It is more complex than that... That is why it is difficult to relate it with an element which does not have direct correlation with the revenues, such as ERM. We should monitor it through the years and the work in general"'- CRD-7.

Some see it from other inclusive aspects, as a conglomerate of factors that create zipper effect.

"The implementation and use of ERM doesn't reduce directly the changes in revenues over the years, but orients the society towards a financial stability, which is also related to the maintenance or what is considered to be a careful increase of the income level". (ACC-1).

\section{Changes In the Company's Value}

The Chief Risk Officers approve the fact that the implementation and use of ERM increases the value of the company by:

- positively influencing the Corporate Governance of the company,
- $\quad$ standardizing all work processes, according to business lines and as a whole,

- enhancing company's reputation in the insurance market and beyond,

- creating a more solid relationship with customers etc.

"I think that the implementation of ERM increases the value of the company because sets a new standard, from which flow all the adequate information for decision making purposes, facilitating the work of the employees and minimizing the risk at the level of the company". (CFO-4).

ERM increases the value of the company, maintaining a sufficient and stable amount of capital.

"The implementation and use of ERM increases the value of the company. It is increasing the value. Increases credibility, creates control standards and improves organizational processes and decision making'. (CRD-2).

\section{Changes In the Methodology Used}

From the implementation in 2015 and further, there have been a lot of changes in the methodology used.

'The implementation of ERM has changed the risk management methodology in our company and the focus has passed from the analysis of the technical financial indicators to a warning process". (ACC-1).

The techniques now are more sophisticated and inclusive (even though as mentioned before there are still problems with the software used). The majority of these companies were using internal rate of returns for each product they were offering, meanwhile now they tend to use more risk based approaches like return on the economic capital. This is not obliged by ERM directly, but indirectly ERM is a strategy that pushes companies to consider risk in all aspects, especially when doing risk profiling for new products. In this sense, it is possible through ERM to allocate capital according to risks, and to reduce some "controllable" risks such as credit or operational risks.

"The aspects of the company that have been influenced mostly by the implementation of ERM in our company have been: the process of premium underwritings, which is now more oriented towards a care and client selection, and the facilitation of the use of applications for the clients at the same time easily managed by the company itself, with minimization of costs and time factor". (ACC-1).

Now the companies are more interested on a sustainable growth, rather than only on growing.

"Before implementing ERM, we as a company were focused only on growing and profits, without considering the risks that come with it. Now we are more responsible, and we put a lot of focus on the risks that come with the increase of sales." 


\section{Changes IN RePORTING PRACTICES}

Risk Management staff have the right to access and consult all the companies' databases. Meanwhile, internal acts regulate the coordination between the structures, as well as the exchange of necessary information according to the areas of responsibilities. Depending on the problems, products (reports, analysis, etc.) that are prepared and distributed, questionnaires are drafted and completed by the central and local structures of society. The data / information collected from the questionnaires are processed by the risk management structures and reflected in the relevant documents / products.

The reports produced by the actuaries (depending also from the profile of each report) are generally usable by all departments and are at the same time presented to the board of directors, or shareholders. The aspects of risk management that are published in the report, include almost all the technical indicators of the company which are at the same time indicators of its level of risk. All the data that is presented in the reports is derived by the data related to the premium income, the level of paid or suspended claims, the insurance costs (including marketing, administrative expenses of the company, etc.

"The main users of ERM reporting seem to be the Major Shareholder/s, Supervisory Board, Senior Management and Operational Management. The aspects of risk management that are published in the report, are all defined in Law no. 52, dated 22. 05. 2014, "On insurance and reinsurance activity", and regulatory acts (ORSA requirements) and for its implementation." (ACC3).

ACC-1 explains that during the period before and after the implementation of ERM, the common changes in the internal risk management reporting were: the frequency of the reports which has increased, and the change in the orientation of risk management which is now more focused on the future. The quality of information has improved essentially, but still a lot of attention, and supervision is needed to be given constantly.

"The frequency of internal risk reporting in our company is on monthly, quarterly, one-year basis, as well as daily reports which are related to events mostly recorded with "alert" signage and that require special supervision and attention. Companies make their internal analyzes for: loss ratio, Insurance Risk Report, Expenditure Report, Retention Report, Capital Change Report, Solvency Margin, etc. and if for any of them there is a deviation from the allowed norms, the company is obliged to provide explanations on the factors that have influenced as well as the measures taken to minimize or avoid negative effects."'-(ACC-1).

The quality of reporting, according to the feedback from the users of risk management information improved, in all respects.

"ERM has improved the way risk is being evidenced and the main factors that influence the process, because the methods of evidence, composition and register of risk are now direct and help the management to take more strategic decisions." (ACC2).
The continuous formal and informal communication with the governing bodies of the company, with the managers of all business lines resulted in a positive impact on the improvement of all reports made for Risk Management by the structures of the Risk Management Directorate. The frequency of internal risk reporting, after the implementation of ERM has increased in these companies with frequencies: quarterly, 6-month, 9-month and annual reports. The main reporting product is the Annual Risk and Solvency SelfAssessment Report.

All the new obligations and regulatory requirements for risk reporting are defined in the following acts of the AFSA:

- Regulation no. 18, dated 28.04.2015, "On the rules of organization of the risk management system in the insurance company",

- Regulation no.55, dated 26.05.2017, "On the supervision of the insurance group",

- AFSA Manual "Supervision with focus on risk", approved by the decision of the AFSA Board no. 132, dated 31.10.2014,

- AFSA Instruction no. 250, dated 28.12.2018, "On the supervision of the insurance group".

\section{Changes in Communicative Aspects AND DECISION-TAKING}

ERM has changed the vision of the companies, making it more strategic and more focused on risk appetite for every possible scenario that may happen. The qualitative and quantitate data provided from the adaption of ERM, has helped the companies to take more strategic decisions and reconsidering their objectives.

"When we were in the process of purchasing three other non-life insurance companies,

ERM helped us with the investment decisions, clarifying for us the risks we were taking. " - (CRD-1).

Strategic "decision making" is co-dependent with capital allocation because strategic decisions have been proved to effect on an appropriate capital allocation.

"for every new strategic risk, our company is willing to take, firstly we calculate the risk appetite and then we decide whether is convenient or not to arrange the needed amount of capital"'-(CRD-3).

\section{Changes in the Arrangement of Actuaries}

The role of the actuary is a key role in risk management processes. They fulfill many roles, and they have a detailed understanding of economic, financial and insurance risks. They develop and use statistical and financial models for financial decision-making objectives, including pricing, establishing the amount of liabilities, and setting capital requirements for possible risks events in future. Actuaries advice shareholder(s) and the board of management on the adequacy of risk assessment, reinsurance arrangements, investment policies, capital levels and stress testing to take in consideration all the possible financial scenarios that may occur. The most handful duty of an actuary is to develop and 
apply models in order to deal with complex financial problems. Actuaries increase the value to the raw output of a software model adding their professional judgment to assess and explain the practical implications of the results and the limitations of the model [23].

The actuary of the company 1 described her work and responsibilities in the company as follows:

"Periodically and continuously calculate the level of PT of the company as well as the adequacy of all indicators related and or indirectly to them. The parameters are analyzed in retrospect in order to create a vision for perspective. From the analysis of indicators, if we have deviations from the allowed and acceptable norms of indicators, make decisions for review of tariffs for products, review of cost indicators, or make proposals for product marketing policies, according to the level of tests of its responsibility. Periodically, the minimum solvency indicators are calculated, on which the calculations are made for the capital and the so lvency of the company, hence the origin for decision-making for capital increase, for the level of dividends, etc."

About the implementation of ERM in her company she responded that:

"ERM is implemented in our company, as an integral part of insurance companies. Our company is the oldest in the market and has an inherited risk culture. The implementation of ERM in our company is an ongoing process and that is dictated by internal indicators and definitely by the supervision of insurance markets" (ACC-1).

\section{ChANGES IN RISK MANAGEMENT DEPARTMENT FUNCTIONS}

The chief of risk management department in non-life insurance companies in Albania has many duties and functions, among which listed above are:

- Representation of the Department in relations with the General Director, other Departments and Branches, and with the authorization of the General Director also with public or private entities.

- Drafting and updating policies, procedures, instructions, etc. for the function, documentation and activity of the department in accordance with the policies of the company and the requirements of the regulators.

- Adherence to all ethical and professional principles in the exercise of his duties.

- Directing and supervising the entire activity of the Department in order to fulfill and perform the duties in compliance with normative, legal and regulatory acts.

- Managing Department resources (including professional qualifications and skills) appropriately, sufficiently, and effectively distributed to fulfill department tasks.

- Clearly define the duties and responsibilities of subordinate staff.

- Directing, training, guiding and controlling staff depending on the performance of their duties.

- Completion of all the reports acquired and based on regulation no. 34 dated 25.05.2015 "On mandatory and periodic reporting of insurance and reinsurance companies":
- Control and reconciliation of premium and claims data with the Department of Finance, Claims Department and Legal Department (for claims that are in litigation) as well as reconciliation for premiums and past claims in reinsurance, for the calculation of technical provisions of premiums and claims every 3 months; premiums for compulsory motor insurance contracts and calculation of technical provisions;

- Risk management of setting risk as they are part of the main risks at the company level.

- Preparation and deposition of physical copies of risks issues which have over $10 \%$ of solvency, including physical copies of optional reinsurance agreements for the reporting period at the Albanian Authority for Financial Supervision.

- Preparation of reports for the reinsurer with the purpose of a possible renewals of reinsurance agreements and adjustments of the property insurance premium, transportation vehicles (including Casco, obligatory insurance, Green Card) according to the client's risk profiles.

- Comparing and analyzing various statistical information, regarding premiums and claims according to the previous experiences of the clients, when this data is required by reinsurers. In certain needed cases, analyzes are made to see if it is necessary to increase the limits of reinsurance agreements.

- Analysis of insurance products and portfolios on annual basis and in cases where they are seen to pose a risk.

- Daily control in the sale system for each product in order to be conform and in accordance with the instructions and regulations, set by default in the legislation of AFSA.

- Under the supervision of Actuarial and Statistics Directorate, to improve (when considered necessary) the preparation of reports and data in the sales and administration system.

During the interview I asked the chief risk officers about the changes in the internal risk management reporting and the main differences that they noticed were:

$\checkmark$ Prior to the implementation of the ERM in the companies, there was no proper internal reporting on Risk Management in these companies. After the implementation has been an increase of the periodic reports on Internal Audit and actuarial issues, as well as periodic work analysis, mainly annual, on the main work dynamics by business lines.

$\checkmark$ With the steps taken these years in these companies for the implementation of ERM, periodic reporting to the Supervisory Board, Senior Management and Operational Management has been realized for all aspects of Risk Management as a whole and according to the business lines.

$\checkmark$ Every year, the Directorate for Risk Management drafts and distributes the Risk Self-Assessment and Solvency Report, which serves as the basis for the Annual Risk Assessment Report that is sent to the FSA. The Risk and Solvency Self-Assessment Report presents in detail the selfassessment of risk and solvency for the company as a whole and according to business lines.

$\checkmark$ An analysis of the impact of external and internal factors on risk management is made, reflecting an overview of risk management in the companies. After the ERM implementation, day-to-day risk management is reflected; and the main issues for risk management are given for the companies and the group. 
$\checkmark$ Events that are thought to have an impact on risk in the future are presented in the reports after the implementation. This revised report provides relevant conclusions and recommendations for the Shareholder, Supervisory Board, Senior Management and Operational Management.

$\checkmark$ In the meantime, the periodic reports on Internal Audit and actuarial issues have been improved and standardized in basis of 3-months, 6-months, 9-months and annual.

$\checkmark$ From the implementation of ERM are standardized and performed 3-months, 6-months, 9-months and annual job analyzes, which are performed according to the Risk Management philosophy. The Risk Management Directorate contributes qualitatively to the preparation of these analyzes.

$\checkmark$ Also, the Information Analysis and Statistics Sector (established during 2019 in some companies) designs and distributes valuable analytical products in order to perform and achieve the strategic and specific objectives of the companies along the business lines.

\section{REFERENCES}

[1] COSO (The Committee of Sponsoring Organisations of the Treadway Commission) (2004a). Enterprise risk management - integrated framework, application techniques. New York: AICPA.

[2] COSO (The Committee of Sponsoring Organizations of the Tread way Commission) (2004b). Enterprise risk management - integrated framework, executive summary. New York: AICPA.

[3] Harner, Michelle M., Barriers to Effective Risk Management (2010). Seton Hall Law Review, Vol. 40, p. 1323, 2010, Maryland Legal Studies Research Paper No. 2010-25.

[4] Beasley, M. S., Clune, R., and Hermanson, D. R. (2005) 'Enterprise Risk Management: An Empirical Analysis of Factors Associated with the Extent of Implementation', Journal of Accounting and Public Policy, 24, pp. 521-531.

[5] Liebenberg, A. P. and Hoyt, R. E. (2003) 'The determinants of Enterprise Risk Management: Evidence from the appointment of Chief Risk Officers', Risk Management and Insurance Review, 6 (1), pp. 3752.

[6] Pagach, D. and Warr, R. (2011), "The characteristics of Firms That Hire Chief Risk Officers', Journal of risk and insurance, 78 (1), pp. 185-211.

[7] Kleffner, A. E., Lee, R. B. and McGannon, B. (2003) 'The Effect of Corporate Governance on the Use of Enterprise Risk Management: Evidence from Canada, Risk Management and Insurance Review, 6 (1), pp. 53-73.

[8] Subramaniam, N., Collier, P., Phang, M., \& Burke, G. (2011). The effects of perceived business uncertainty, external consultants and risk management on organizational outcomes. Journal of Accounting and Organizational Change, 7(2), 132-157.

[9] Colquitt, L. L., Hoyt, R. E. and Lee, R. B. (1999) 'Integrated Risk Management and the Role of the Risk Manager', Risk Management and Insurance Review, 2(3), pp. 43-61.

[10] Tillinghast-Towers Perrin (2004). Adding Value Through Risk and Capital Management. New York: Tillinghast-Towers Perrin. [10] Meulbroek, L. (2002) 'The Promise And Challenge of Integrated Risk Management', Risk Management and Insurance Review, 5(1), pp. 5566.

[11] Shim, J. (2007). Capital Allocation and the Price of Insurance: Evidence from the Merger and Acquisition Activity in the U. S. Property-Liability Insurance Industry. Georgia State University Atlanta, Working paper, United States.

[12] Myers, S. C. and Read, J. A. (2001) 'Capital allocation for insurance companies', Journal of Risk and Insurance (December), 68 (4), pp. $545-580$.

[13] AON (2010). Global Enterprise Risk Management 15Survey. Chicago: AON Corporation.

[14] Ashby, S., Palermo, T., and Power, M. (2013). Risk Culture in Financial Organizations- An Interim Report. Centre for analysis of risk and regulation (CARR), LSE, discussion paper pp. 1-25, London, November.

[15] Britton, N. R. (2001) Enhancing Shareholder Value through Capital Risk Management: proceedings of a conference sponsored by Aon Re Australia Limited. Sydney. Australia: Aon Re Australia Ltd.
[16] Pagach, D. and Warr, R. (2008). The Effects of Enterprise Risk Management on Firm Performance. North Carolina State University, Working paper, June.

[17] [17] Collis, J. and Hussey, R. (2003) Business Research a Practical Guide for Undergraduate and Postgraduate Students. $2^{\text {nd }}$ edn. London: Macmillan Press Ltd.

[18] Burns, J., Ezzamel, M. and Scapens, R. W. (2003) The Challenge of Management Accounting Change: Behavioural and Cultural Aspects of Change Management. London: Chartered Institute of Management Accountants.

[19] Lillis, A. M. and Mundy, J. (2005) 'Cross-Sectional Field Studies in Management Accounting Research-Closing the Gaps between Surveys and Case Studies', Journal of management accounting research, 17, pp. 119-141.

[20] Ryan, G. W. and Bernard, R. H. (2003) 'Data Management and Analysis Methods', in Denzin, N. K. and Lincoln, Y. S. (eds.), Collecting and Interpreting Qualitative Materials. London: Sage, pp. 259-309.

[21] Silverman, D. (2009) Doing qualitative research, A Practical Handbook. London: Sage.

[22] Creswell, J. W. (2009) Research design: Qualitative, quantitative, and mixed methods approaches. $3^{\text {rd }}$ edition. Thousand Oaks, CA: SAGE Publications.

[23] International Actuarial Association (2013) Actuarial Viewpoints on and Roles in Systemic Risk Regulation in Insurance Markets.

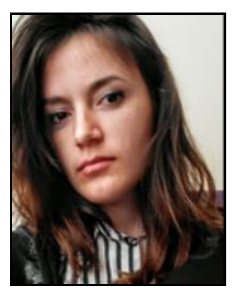

Armanda Tola was born in Albania, on 17 April 1991 She finished her Bachelor and Master of Science studies (2014) in the University of Tirana, Faculty of Economy. She has worked as teaching and research assistant for some years and now is a lecturer in a private university in Albania. She has also worked for three years in a nonlife insurance company in the Finance Department. She is currently pursuing her Ph.D. in Risk Management from the American College of Skopje, North Macedonia. 